Article

\title{
Inpatient Burden of Prurigo Nodularis in the United States
}

\author{
Katherine A. Whang ${ }^{1}\left(\mathbb{D}\right.$, Sewon Kang ${ }^{1}$ and Shawn G. Kwatra ${ }^{1,2, *(D)}$ \\ 1 Department of Dermatology, Johns Hopkins University School of Medicine, Baltimore, MD 21205, USA \\ 2 Department Bloomberg School of Public Health, Johns Hopkins Bloomberg School of Public Health, \\ Baltimore, MD 21205, USA \\ * Correspondence: skwatra1@jhmi.edu; Tel.: +1-410-955-8662
}

Received: 29 June 2019; Accepted: 8 August 2019; Published: 11 August 2019

\begin{abstract}
Background: Although prurigo nodularis (PN) has a significant burden of disease, little is known about its epidemiology and disease burden within the United States. We describe the characteristics of hospitalized patients diagnosed with PN and assess the factors associated with hospitalization. Methods: We performed a cross-sectional study of the 2016 National Inpatient Sample, a representative sample of $20 \%$ of hospital discharges nationally. Results: Patients diagnosed with PN accounted for 3.7 inpatient visits per 100,000 discharges nationally in 2016. Patients with PN were more likely to be black (odds ratio (OR) 4.43, 95\% CI (3.33-6.08), $p<0.001$ ) or Asian (OR $3.44,95 \%$ CI (1.39-5.08), $p=0.003)$ compared with white patients. Patients diagnosed with PN had both a longer length of hospital stay (mean \pm SD, $6.51 \pm 0.37$ days vs. $4.62 \pm 0.02$ days, $p<0.001$ ) and higher cost of care $(\$ 14,772 \pm \$ 964$ vs. $\$ 11,728 \pm \$ 106, p<0.001)$ compared with patients without PN. Patients with PN were significantly more likely to be admitted for HIV complications (OR 78.2, 95\% CI (46.4-131.8), $p<0.001)$. PN contributes to increased inpatient cost of care and length of hospitalization. Conclusions: There are racial disparities associated with hospital admission of patients diagnosed with PN.
\end{abstract}

Keywords: prurigo nodularis; pruritus; itch; inpatient; disease burden; national inpatient sample

\section{Introduction}

Prurigo nodularis (PN) is a chronic pruritic condition that is characterized by repeated scratching behavior and the presence of multiple, intensely itchy nodules [1]. These lesions often are excoriated to the point of ulceration and are symmetrically distributed on the extensor surfaces of the limbs and trunk [2]. PN has a significant impact on the quality of life and is linked with numerous systemic and psychological comorbidities, such as anxiety, depression, and sleep disturbance, as has been found with other pruritic conditions, like atopic dermatitis [3-7]. Recent studies on the pathogenetic mechanisms of PN has revealed the importance of pro-inflammatory cytokines, such as IL-31, and neuropeptides in lesional skin that may contribute to altered nerve density and increased inflammation in PN [8-10]. Despite the tremendous burden of disease of PN, there is very little known about the etiology and epidemiology of PN. A German study examined 108 PN patients in a predominantly Caucasian population and observed a female predominance (64\%) with a median age of 61.5 years and found that more than half of PN cases had an atopic predisposition or concomitant atopic dermatitis [2]. In fact, Tanaka et al describe two distinct forms of PN: An early-onset atopic form and a late-onset non-atopic form [11]. Our group also recently described a cohort of PN patients seen in the Johns Hopkins Health System, though epidemiologic conclusions are difficult to draw based on a single health system experience [5,12]. 
One potential reason for the limited amount of epidemiologic data available is that PN is fairly uncommon, and in the past was grouped together with other chronic pruritic conditions in previous disease classification systems [1]. However, in 2015, the United States transitioned to the new disease classification system, International Classification of Diseases, Tenth Revision, Clinical Modification (ICD-10-CM), from the previously used ICD-9-CM, allowing for increased specificity in disease coding. For the first time, PN received a dedicated diagnosis code, enabling new avenues for epidemiologic research on $\mathrm{PN}$ to be explored.

Previous studies have demonstrated an association between PN and several comorbidities, such as HIV infection, hepatitis, congestive heart failure, chronic kidney disease, Type 2 diabetes mellitus, and several psychiatric conditions [5]. These conditions contribute to PN's burden of disease and may affect hospitalization and cost of care. Due to the limited research on PN as a disease entity, little is known on the inpatient burden of PN in the United States. In the current study, we analyze the epidemiology and inpatient burden of PN in the United States, as well as factors associated with hospitalization for PN in a nationally representative database of hospitalizations in 2016.

\section{Materials and Methods}

\subsection{Data Source}

We analyzed data from the National Inpatient Sample (NIS) from 2016. The NIS is administered by the Healthcare Cost and Utilization Project (HCUP) of the Agency for Healthcare Research and Quality. Each year of data represented a stratified sample of approximately $20 \%$ of all inpatient hospitalizations within the United States. Of note, 2016 was the first complete year that prurigo nodularis received an independent diagnostic code as detailed below. Sample weights provided by NIS were used to account for sampling design of hospitals to determine nationally representative estimates. The study was exempt from the institutional review board because the database was deidentified before use.

\subsection{Selection of Prurigo Nodularis Cohort}

Patients with a diagnosis of prurigo nodularis were selected using ICD-10-CM codes. An ICD-10-CM code of L28.1 corresponded to a diagnosis of prurigo nodularis.

\subsection{Statistical Analysis}

Data analysis was performed using survey models that accounted for NIS-provided survey weights, sampling clusters, and strata using Stata version 15 (StataCorp, College Station, TX, USA). We determined the estimated prevalence of hospitalization for PN. Cost of inpatient care was determined based on the total reported charge of hospitalization and the all-payer inpatient cost-to-charge ratio estimates for hospitals provided by HCUP.

The control group included all discharges with no diagnosis of $\mathrm{PN}$, representing the population of hospitalized patients in the United States. In order to determine risk factors for hospitalization of patients diagnosed with PN, binary logistic models were constructed using hospitalization with PN as the dependent variable. Independent variables included age, gender, race/ethnicity, the median annual income of the hospital ZIP code, health insurance type, season of admission, hospital location, teaching status, and hospital bed capacity. A $p$-value of $<0.05$ was considered significant with Bonferroni correction.

\section{Results}

There was a total of 7,135,090 discharges reported in the NIS dataset during 2016. There were 265 hospitalized patients with a diagnosis of PN (weighted 1325, 95\% confidence interval (CI) (1120-1530)) or 3.7 inpatient visits per 100,000 discharges in 2016. 


\subsection{Factors Associated with Hospitalization for Prurigo Nodularis}

Patients admitted as inpatients to hospitals with a diagnosis of PN were on average older than patients without a diagnosis of PN (mean \pm SD $55.2 \pm 0.9$ years vs. $49.0 \pm 0.2$ years, respectively). Patients with PN were more likely to be black (survey-weighted logistic regression; odds ratio (OR) 4.43, 95\% CI (3.33-6.08), $p<0.001$ ), Hispanic (OR 1.77, 95\% CI (1.09-2.88), $p=0.02)$, or Asian (OR $3.44,95 \%$ CI (1.39-5.08), $p=0.003$ ) compared with white patients (Figure 1). Black PN patients were more likely to be male than black patients of the general patient population $(59.1 \%$ vs. $41.1 \%$; OR 1.97 , 95\% CI (1.36-2.85), $p=0.0003)$. PN patients were also more likely to have Medicare (OR 2.81, 95\% CI (1.80-4.39), $p<0.001$ ) or Medicaid (OR 2.24, 95\% CI (1.44-3.47), $p<0.001$ ), as compared to patients with private insurance. In the US, Medicare and Medicaid are government-run programs that provide health insurance to the elderly and low-income. Hospitalized patients with PN were more likely to be seen in teaching hospitals (OR 2.60, 95\% CI (1.76-3.84), $p<0.001$ ) compared to non-teaching and hospitals with a large bed capacity (OR 2.15, 95\% CI (1.41-3.27), $p<0.001)$.

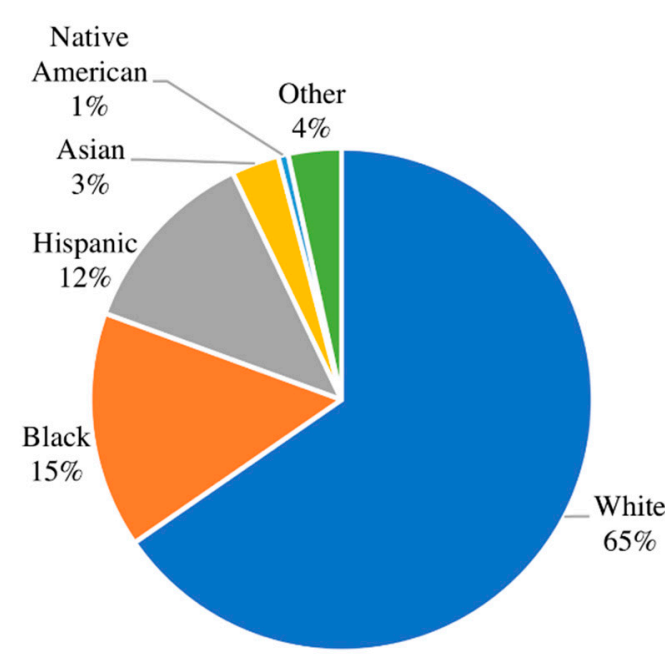

No Prurigo Nodularis

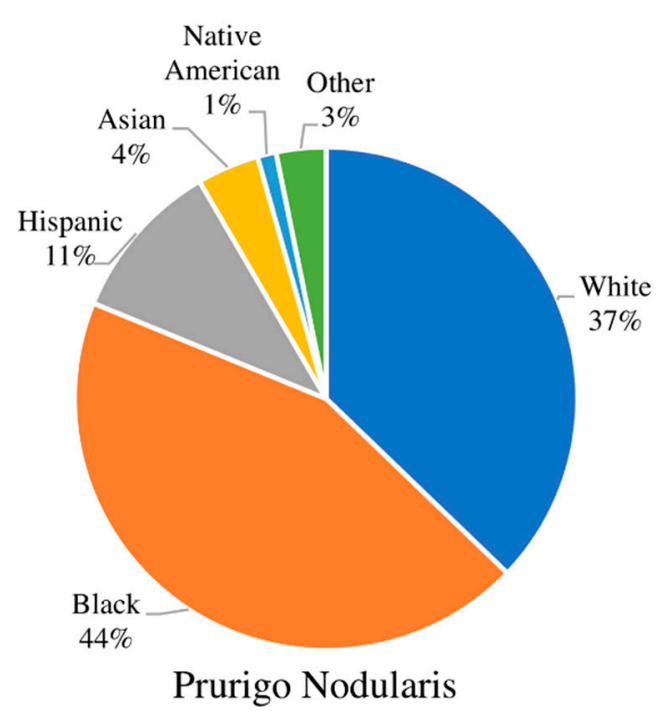

Figure 1. Comparison of racial distribution. The racial distribution of patients with no prurigo nodularis (left) compared to patients with prurigo nodularis (right). The population of prurigo nodularis patients is disproportionately black compared to patients with no prurigo nodularis.

In multivariate logistic regression models with stepwise elimination, age, race/ethnicity, insurance status, teaching status, and hospital bed size were found to have a statistically significant contribution to hospitalization for PN (Table 1). The factors of sex, income quartile, season, and hospital region were found to have no statistically significant contribution to hospitalization for PN. 
Table 1. Demographics of hospitalized patients with a diagnosis of prurigo nodularis compared to the general inpatient population without a diagnosis of prurigo nodularis.

\begin{tabular}{|c|c|c|c|c|c|c|}
\hline \multirow{2}{*}{ Variable } & \multicolumn{2}{|c|}{$\begin{array}{l}\text { General Inpatient Population without a } \\
\text { Diagnosis of Prurigo Nodularis }\end{array}$} & \multicolumn{2}{|c|}{ Patients with Prurigo Nodularis } & \multirow{2}{*}{ Adjusted OR } & \multirow{2}{*}{$p$-Value } \\
\hline & Est. Frequency & $\begin{array}{c}\text { Percent }(95 \% \\
\text { Confidence Interval) }\end{array}$ & Est. Frequency & $\begin{array}{c}\text { Percent }(95 \% \\
\text { Confidence Interval) }\end{array}$ & & \\
\hline $0-17$ & $5,479,694$ & 15.3 [14.9-15.9] & 5 & $0.38[0.05-2.64]$ & 0.04 & 0.002 \\
\hline $18-39$ & $7,423,759$ & $20.8[20.5-21.0]$ & 210 & 15.8 [11.8-20.9] & 1.00 & - \\
\hline $40-59$ & $7,403,610$ & $20.7[20.5-21.0]$ & 620 & $46.8[40.2-53.5]$ & 2.95 & $<0.001$ \\
\hline $60-79$ & $10,515,272$ & $29.4[29.0-29.7]$ & 390 & $29.4[24.0-35.5]$ & 1.34 & 0.263 \\
\hline$>80$ & $4,886,856$ & 13.7 [13.5-13.9] & 100 & $7.55[4.83-11.60]$ & 0.75 & 0.386 \\
\hline \multicolumn{7}{|l|}{ RACE } \\
\hline White & $22,141,260$ & $65.4[64.4-66.3]$ & 464 & $37.2[30.8-44.1]$ & 1.00 & - \\
\hline Black & $5,145,981$ & $15.2[14.6-15.8]$ & 550 & $44.0[37.1-51.1]$ & 4.43 & $<0.001$ \\
\hline Hispanic & $4,150,991$ & $12.3[11.6-12.9]$ & 130 & $10.4[6.9-15.4]$ & 1.77 & 0.02 \\
\hline Asian & $1,037,020$ & 3.06 [2.83-3.32] & 50 & $4.00[2.22-7.09]$ & 2.66 & 0.003 \\
\hline Other & $1,156,259$ & $3.42[3.12-3.74]$ & 40 & 3.20 [1.63-6.20] & 1.29 & 0.586 \\
\hline \multicolumn{7}{|l|}{ GENDER } \\
\hline Female & $15,439,345$ & 43.3 [43.1-43.5] & 635 & 47.9 [41.7-54.2] & 1.00 & - \\
\hline Male & $20,236,076$ & 56.7 [56.5-56.9] & 690 & 52.1 [45.8-58.3] & 1.00 & 0.75 \\
\hline \multicolumn{7}{|l|}{ SEASON } \\
\hline Winter & $8,914,808$ & $25.0[25.0-25.0]$ & 400 & $30.2[24.9-36.1]$ & 1.00 & - \\
\hline Spring & $9,015,068$ & 25.3 [25.2-25.3] & 315 & 23.8 [19.3-29.0] & 0.81 & 0.213 \\
\hline Summer & $8,914,118$ & $25.0[25.0-25.0]$ & 305 & 23.0 [18.2-28.7] & 0.73 & 0.106 \\
\hline Fall & $8,796,723$ & 24.7 [24.6-24.7] & 270 & 20.4 [15.9-25.8] & 0.72 & 0.063 \\
\hline
\end{tabular}


Table 1. Cont.

\begin{tabular}{|c|c|c|c|c|c|c|}
\hline \multirow{2}{*}{ Variable } & \multicolumn{2}{|c|}{$\begin{array}{l}\text { General Inpatient Population without a } \\
\text { Diagnosis of Prurigo Nodularis }\end{array}$} & \multicolumn{2}{|c|}{ Patients with Prurigo Nodularis } & \multirow{2}{*}{ Adjusted OR } & \multirow{2}{*}{$p$-Value } \\
\hline & Est. Frequency & $\begin{array}{c}\text { Percent }(95 \% \\
\text { Confidence Interval) }\end{array}$ & Est. Frequency & $\begin{array}{c}\text { Percent }(95 \% \\
\text { Confidence Interval) }\end{array}$ & & \\
\hline First & $10,774,519$ & $30.7[29.8-31.6]$ & 465 & $36.9[30.4-43.9]$ & 1.00 & - \\
\hline Second & $8,915,683$ & $25.4[24.8-26.0]$ & 270 & $21.4[16.5-27.3]$ & 0.98 & 0.929 \\
\hline Fourth & $6,999,502$ & $20.0[19.0-20.9]$ & 235 & $18.7[13.2-24.0]$ & 1.38 & 0.112 \\
\hline \multicolumn{7}{|l|}{ INSURANCE } \\
\hline Medicare & $14,127,590$ & $39.6[39.1-40.1]$ & 645 & $49.0[42.8-55.4]$ & 2.81 & $<0.001$ \\
\hline Medicaid & $8,241,094$ & $23.1[22.6-23.7]$ & 370 & $28.1[22.7-34.3]$ & 2.24 & $<0.001$ \\
\hline Private & $10,734,828$ & $30.1[29.6-30.6]$ & 205 & $15.6[11.6-20.7]$ & 1.00 & - \\
\hline Self-pay & $1,377,983$ & $3.87[3.71-4.03]$ & 65 & $4.94[2.84-8.48]$ & 1.61 & 0.238 \\
\hline Other & $1,058,214$ & $2.97[2.77-3.19]$ & 30 & 2.28 [1.03-4.96] & 1.28 & 0.612 \\
\hline \multicolumn{7}{|l|}{ INSURED } \\
\hline Yes & $33,078,581$ & 92.7 [92.5-92.9] & 1,220 & 92.1 [88.0-94.9] & 1.00 & - \\
\hline No & $1,377,983$ & 3.86 [3.70-4.03] & 65 & $4.91[2.81-8.42]$ & 1.00 & - \\
\hline Other or no charge & $1,170,174$ & 3.28 [3.07-3.50] & 30 & 2.26 [1.03-4.92] & 1.00 & - \\
\hline \multicolumn{7}{|l|}{ REGION } \\
\hline Northeast & $6,599,084$ & 18.5 [17.9-19.2] & 270 & 20.4 [15.3-26.6] & 1.00 & - \\
\hline Midwest & $7,933,647$ & 22.2 [21.6-22.9] & 355 & $26.8[20.2-34.6]$ & 1.38 & 0.14 \\
\hline South & $14,041,126$ & $39.3[38.5-40.1]$ & 445 & 33.6 [26.6-41.3] & 0.91 & 0.649 \\
\hline West & $7,122,759$ & 20.0 [19.4-20.6] & 255 & 19.2 [14.0-25.9] & 1.25 & 0.328 \\
\hline
\end{tabular}


Table 1. Cont

\begin{tabular}{|c|c|c|c|c|c|c|}
\hline \multirow{2}{*}{ Variable } & \multicolumn{2}{|c|}{$\begin{array}{l}\text { General Inpatient Population without a } \\
\text { Diagnosis of Prurigo Nodularis }\end{array}$} & \multicolumn{2}{|c|}{ Patients with Prurigo Nodularis } & \multirow{2}{*}{ Adjusted OR } & \multirow{2}{*}{$p$-Value } \\
\hline & Est. Frequency & $\begin{array}{c}\text { Percent (95\% } \\
\text { Confidence Interval) }\end{array}$ & Est. Frequency & $\begin{array}{c}\text { Percent (95\% } \\
\text { Confidence Interval) }\end{array}$ & & \\
\hline Nonteaching & $23,291,422$ & $65.4[64.7-66.1]$ & 1,130 & $85.3[79.9-89.4]$ & 1.00 & - \\
\hline Teaching & $12,320,949$ & $34.6[33.9-35.3]$ & 195 & $14.7[10.6-20.1]$ & 2.60 & $<0.001$ \\
\hline Small & $6,674,756$ & 18.7 [18.1-19.3] & 170 & 12.8 [9.1-17.7] & 1.00 & - \\
\hline Medium & $10,351,226$ & $29.0[28.4-29.7]$ & 240 & $18.1[13.3-24.2]$ & 1.13 & 0.629 \\
\hline Large & $18,632,207$ & $52.2[51.5-53.0]$ & 915 & $69.1[62.1-75.2]$ & 2.15 & $<0.001$ \\
\hline
\end{tabular}




\subsection{Length of Stay and Cost of Care}

The length of stay (LOS) in the hospital was longer in duration for patients with a diagnosis of PN compared with patients without PN (mean \pm SD, $6.51 \pm 0.37$ days vs. $4.62 \pm 0.02$ days, $p<0.001$ ). In multivariate linear regression for LOS in patients diagnosed with PN, older age ( $\geq 18$ years) was associated with a longer duration of hospital stay (beta coefficient $=3.46,95 \%$ CI [0.93-5.99], $p=0.007$ ) (Table 2).

Table 2. Multivariate linear regression for the cost of care and length of stay among prurigo nodularis patients.

\begin{tabular}{|c|c|c|c|c|c|c|}
\hline \multirow{2}{*}{ Demographic } & \multicolumn{3}{|c|}{ Cost of Care } & \multicolumn{3}{|c|}{ Length of Stay } \\
\hline & Adjusted Beta & $95 \%$ CI & $p$-Value & $\begin{array}{c}\text { Adjusted } \\
\text { Beta }\end{array}$ & $95 \% \mathrm{CI}$ & $p$-Value \\
\hline \multicolumn{7}{|l|}{ AGE, $y$} \\
\hline $0-17$ & Reference & & & & & \\
\hline $18-39$ & 8980.12 & [2271.54-15688.7] & 0.009 & 3.46 & [0.93-5.99] & 0.007 \\
\hline $40-59$ & 10306.25 & [3295.591-17316.91] & 0.004 & 2.72 & {$[0.20-5.24]$} & 0.034 \\
\hline $60-79$ & 17129.11 & [8512.382-25745.83] & $<0.001$ & 3.74 & [0.99-6.50] & 0.008 \\
\hline$>80$ & 7701.64 & [-1590.12-16993.42] & 0.104 & 1.06 & {$[-2.43-4.57]$} & 0.55 \\
\hline \multicolumn{7}{|l|}{ SEASON } \\
\hline Winter & Reference & & & & & \\
\hline Spring & 2428.98 & [-3651.91-8509.88] & 0.433 & 0.34 & {$[-2.05-2.74]$} & 0.776 \\
\hline Summer & -2276.29 & {$[-6883.1-2330.51]$} & 0.333 & -2.08 & {$[-4.08--0.08]$} & 0.041 \\
\hline Fall & -1365.68 & [-6400.697-3669.33] & 0.595 & -2.06 & {$[-4.28-0.15]$} & 0.069 \\
\hline \multicolumn{7}{|l|}{ GENDER } \\
\hline Female & Reference & & & & & \\
\hline Male & -2927.89 & [-7155.95-1300.16] & 0.175 & -0.23 & {$[-1.84-1.38]$} & 0.781 \\
\hline \multicolumn{7}{|l|}{ RACE } \\
\hline White & Reference & & & & & \\
\hline Black & -696.01 & {$[-5725.16-4333.13]$} & 0.786 & 0.18 & {$[-2.06-2.42]$} & 0.875 \\
\hline Hispanic & 2806.11 & [-4865.536-10477.76] & 0.473 & -0.28 & {$[-2.97-2.42]$} & 0.841 \\
\hline Asian & 5474.29 & {$[-1684.91-12633.5]$} & 0.134 & -0.38 & {$[-3.27-2.50]$} & 0.794 \\
\hline $\begin{array}{c}\text { Native } \\
\text { American }\end{array}$ & 5100.59 & [-9957.69-20158.88] & 0.507 & 4.44 & [-3.10-11.99] & 0.248 \\
\hline Other & -6695.23 & {$[-14271.62-881.14]$} & 0.083 & -2.55 & {$[-5.51-0.41]$} & 0.092 \\
\hline \multicolumn{7}{|l|}{$\begin{array}{c}\text { INCOME } \\
\text { QUARTILE }\end{array}$} \\
\hline First & Reference & & & & & \\
\hline Second & 1357.71 & [-4561.79-7277.22] & 0.653 & 1.47 & {$[-1.26-4.20]$} & 0.29 \\
\hline Third & -326.29 & [-4849.39-4196.79] & 0.888 & 0.25 & [-1.59-2.09] & 0.793 \\
\hline Fourth & 2211.26 & [-5600.19-10022.73] & 0.579 & -0.41 & {$[-2.73-1.90]$} & 0.725 \\
\hline \multicolumn{7}{|l|}{ INSURANCE } \\
\hline Medicare & 3799.07 & [-2029.32-9627.46] & 0.201 & 2.14 & {$[-0.31-4.59]$} & 0.87 \\
\hline Medicaid & 4274.12 & [-666.47-9214.72] & 0.09 & 2.14 & {$[-0.07-4.35]$} & 0.058 \\
\hline Private & Reference & & & & & \\
\hline Self-pay & -200.49 & {$[-6367.36-5966.37]$} & 0.949 & 0.23 & {$[-2.88-3.32]$} & 0.886 \\
\hline \multicolumn{7}{|l|}{ No charge } \\
\hline Other & 355.35 & {$[-8232.30-8943.01]$} & 0.935 & 3.37 & {$[-0.96-7.70]$} & 0.127 \\
\hline
\end{tabular}


Table 2. Cont.

\begin{tabular}{|c|c|c|c|c|c|c|}
\hline \multirow{2}{*}{ Demographic } & \multicolumn{3}{|c|}{ Cost of Care } & \multicolumn{3}{|c|}{ Length of Stay } \\
\hline & Adjusted Beta & $95 \%$ CI & $p$-Value & $\begin{array}{l}\text { Adjusted } \\
\text { Beta }\end{array}$ & $95 \%$ CI & $p$-Value \\
\hline \multicolumn{7}{|l|}{ REGION } \\
\hline Northeast & Reference & & & & & \\
\hline Midwest & 1947.42 & [-5246.55-9141.39] & 0.596 & -0.84 & {$[-3.76-2.08]$} & 0.573 \\
\hline South & 951.9 & [-4984.18-6888.00] & 0.753 & 0.12 & {$[-2.44-2.68]$} & 0.929 \\
\hline West & 2914.19 & {$[-4681.94-10510.34]$} & 0.452 & -0.48 & {$[-3.35-2.40]$} & 0.745 \\
\hline \multicolumn{7}{|l|}{$\begin{array}{l}\text { TEACHING } \\
\text { STATUS }\end{array}$} \\
\hline Nonteaching & Reference & & & & & \\
\hline Teaching & 1639.64 & [-2697.30-5976.59] & 0.459 & -0.22 & {$[-2.15-1.70]$} & 0.819 \\
\hline \multicolumn{7}{|l|}{$\begin{array}{c}\text { HOSPITAL } \\
\text { BED } \\
\text { CAPACITY }\end{array}$} \\
\hline Small & Reference & & & & & \\
\hline Medium & 5096.48 & [-1453.24-11646.2] & 0.127 & 0.51 & {$[-2.35-3.37]$} & 0.727 \\
\hline Large & 7446.41 & [1527.81-13365.01] & 0.014 & 0.6 & {$[-1.57-2.77]$} & 0.587 \\
\hline
\end{tabular}

The total cost of care for hospitalized patients diagnosed with PN was $\$ 18,686,522$ in 2016 ; however, the actual total cost was higher because 12 patients had missing values for cost. The average cost of care was higher in patients diagnosed with PN compared with patients without PN (\$14,772 \pm \$964 vs. $\$ 11,728 \pm \$ 106, p<0.001)$. In multivariate linear regression for cost of care in patients diagnosed with PN, older age ( $\geq 18$ years) was associated with increased cost (age under 18 years: Beta coefficient $=$ $\$ 8,980,95 \%$ CI $(2,271.54-15,688.7), p=0.009)$ (Table 2).

\subsection{Primary Reason for Admission of Prurigo Nodularis Patients}

The most common reasons for admission to the hospital for patients diagnosed with PN were sepsis $(11.7 \%)$, cellulitis (7.9\%), acute exacerbation of congestive heart failure (7.5\%), HIV (5.7\%), pneumonia (3.4\%), and end stage renal disease (3.0\%) (Figure 2). Patients with PN were significantly more likely to be admitted due to HIV complications compared to the general inpatient population (OR 78.2, 95\% CI (46.4-131.8), $p<0.001)$. Furthermore, PN patients with concomitant HIV were significantly more likely to be black than white (OR 8.2, 95\% CI (1.02-66.0), $p=0.048)$.

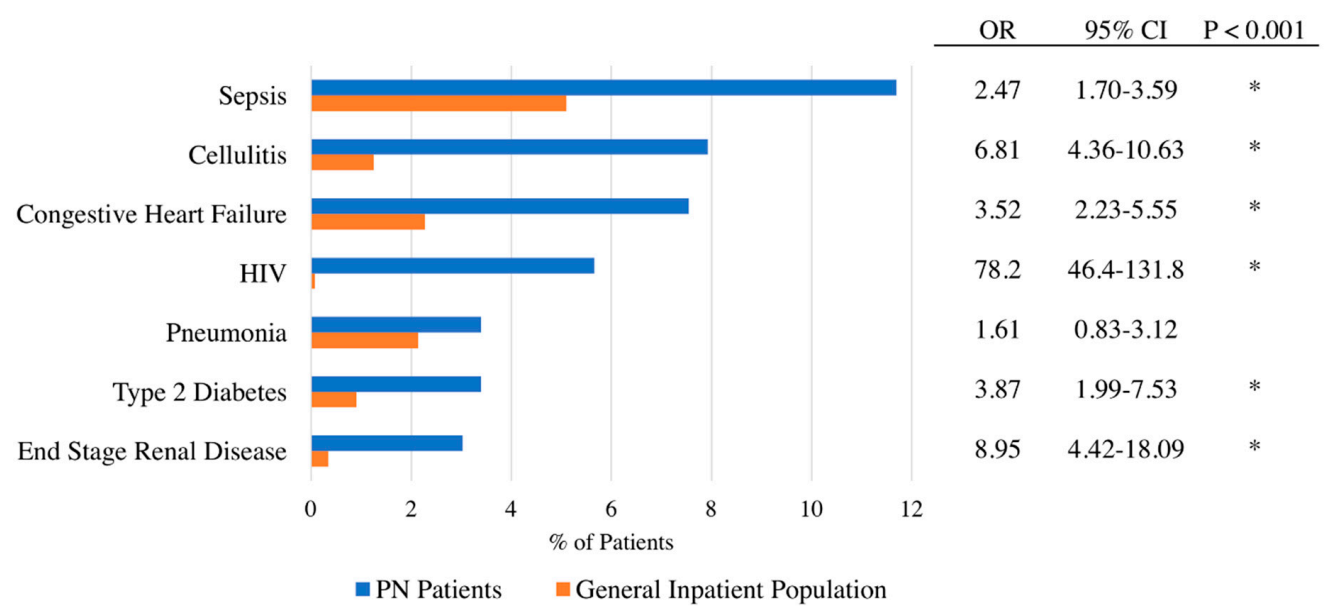

Figure 2. Comparison of primary admission reason. Primary admission reason for prurigo nodularis patients compared to patients with no prurigo nodularis. 


\section{Discussion}

This study represents the first epidemiological investigation of PN employing a national dataset in the United States to be reported in the literature. We estimate that approximately 1325 patients diagnosed with PN were hospitalized in the United States in 2016 or 3.7 inpatients per 100,000 discharges. These PN patients had both longer hospital stays and increased costs of care as compared to the general inpatient population. This is likely to be an underestimation of the overall PN inpatient burden as there is a lack of disease awareness among most physicians, and many patients do not receive inpatient dermatology consultations. We demonstrate that PN patients are more likely than the general population to be older in age, particularly in the 40 to 59 years age range and that increased age was associated with longer hospital stay and increased the cost of care. We attribute these age-related differences to the increased concomitant systemic comorbidities with age, such as diabetes mellitus and chronic kidney disease, which are systemic causes themselves of chronic pruritus and have been found to be associated with PN [5].

Our study also demonstrates increased rates of hospitalization in PN patients who were non-white, demonstrating racial disparities in the presentation of PN. In particular, these results confirmed recent findings indicating that PN disproportionately affected blacks [5]. Indeed, among the different races studied, blacks had the greatest likelihood of having PN. As previously described, black PN patients were also more likely than whites, Asians, or Hispanics to have concomitant HIV infection [5]. We found that black patients with a PN diagnosis were significantly more likely to be male compared to the general population of black patients. Recent findings have demonstrated that out of all new HIV diagnoses to black individuals in $2017,76 \%$ were male, which may explain the increased likelihood of black males with PN [13].

Interestingly, infections including cellulitis and sepsis were frequent reasons for admission among patients with PN. Excoriation of skin nodules to the point of ulceration may serve as a nidus for infection in PN patients. In addition, given that PN is reported to have a positive predictive value for a CD4 count of <200 among HIV patients [14], PN patients are also likely to be at greater risk of infection because of more frequent rates of immunosuppression. Increased frequency of end stage renal disease and congestive heart failure as reasons for admission are also consistent with prior studies showing an association between cardiovascular and renal comorbidities in patients with PN $[5,15,16]$.

Strengths of this study include the use of a nationally representative dataset with over 7 million records. Given the recent transition from ICD-9-CM to ICD-10-CM, this is the first study that provides epidemiologic data on PN in the United States. Weaknesses include the small PN sample size given the under-recognition of PN by non-dermatologic specialties. Effects of disease severity and treatment on hospitalization could also not be determined.

In conclusion, our study characterizes the inpatient burden of PN in the United States and demonstrates increased cost and length of hospital stay in the care of these patients. Our study also confirms racial differences in the burden of PN, with PN patients most likely to be black. PN patients were also found to be more likely to be admitted for infections and comorbid cardiovascular and renal conditions. Additional studies are needed to further characterize the ambulatory disease burden of PN.

Author Contributions: Conceptualization, K.A.W., S.K. and S.G.K.; data curation, K.A.W. and S.G.K.; formal analysis, K.A.W.; funding acquisition, S.G.K.; investigation, K.A.W. and S.G.K.; methodology, K.A.W. and S.G.K.; supervision, S.K. and S.G.K.; validation, K.A.W.; writing-original draft, K.A.W. and S.G.K.; writing-review and editing, K.A.W., S.K. and S.G.K.

Funding: This research received no external funding.

Institutional Review Board Status: IRB approval was waived as only anonymous aggregate level data were used.

Acknowledgments: Kwatra received a research grant from the Skin of Color Society and is a recipient of a Medical Dermatology Career Development Award from the Dermatology Foundation.

Conflicts of Interest: S.G.K. is an advisory board member for Menlo and Trevi Therapeutics and has received grant funding from Kiniksa Pharmaceuticals. S.K. is an advisory board member for Menlo Therapeutics. 


\section{References}

1. Pereira, M.P.; Steinke, S.; Zeidler, C.; Forner, C.; Riepe, C.; Augustin, M.; Bobko, S.; Dalgard, F.; Elberling, J.; Garcovich, S.; et al. European academy of dermatology and venereology European prurigo project: Expert consensus on the definition, classification and terminology of chronic prurigo. J. Eur. Acad. Dermatol. Venereol. 2018, 32, 1059-1065. [CrossRef] [PubMed]

2. Klein, D.; Phan, N.Q.; Grundmann, S.; Chatzigeorgakidis, E.; Iking, A.; Ständer, S. Prurigo as a symptom of atopic and non-atopic diseases: Aetiological survey in a consecutive cohort of 108 patients. J. Eur. Acad. Dermatol. Venereol. 2012, 27, 550-557.

3. Konda, D.; Chandrashekar, L.; Rajappa, M.; Kattimani, S.; Thappa, D.M.; Ananthanarayanan, P.H. Serotonin and interleukin-6: Association with pruritus severity, sleep quality and depression severity in Prurigo Nodularis. Asian J. Psychiatry 2015, 17, 24-28. [CrossRef] [PubMed]

4. Schneider, G.; Driesch, G.; Heuft, G.; Evers, S.; Luger, T.A.; Ständer, S. Psychosomatic cofactors and psychiatric comorbidity in patients with chronic itch. Clin. Exp. Dermatol. 2006, 31, 762-767. [CrossRef] [PubMed]

5. Boozalis, E.; Tang, O.; Patel, S.; Semenov, Y.R.; Pereira, M.P.; Stander, S.; Kang, S.; Kwatra, S.G. Ethnic differences and comorbidities of 909 prurigo nodularis patients. J. Am. Acad. Dermatol. 2018, 79, 714-719. [CrossRef] [PubMed]

6. Boccardi, D.; D'Auria, E.; Turati, F.; DI Vito, M.; Sortino, S.; Riva, E.; Cerri, A. Disease severity and quality of life in children with atopic dermatitis: PO-SCORAD in clinical practice. Minerva Pediatr. 2017, 69, 373-380. [PubMed]

7. Coutanceau, C.; Stalder, J. Analysis of Correlations between Patient-Oriented SCORAD (PO-SCORAD) and Other Assessment Scores of Atopic Dermatitis Severity. Dermatology 2014, 229, 248-255. [CrossRef] [PubMed]

8. Kneiber, D.; Valdebran, M.; Amber, K.T. Treatment-resistant prurigo nodularis: Challenges and solutions. Clin. Cosmet. Investig. Dermatol. 2019, 12, 163-172.

9. Sonkoly, E.; Muller, A.; Lauerma, A.I.; Alenius, H.; Dieu-nosjean, M.; Meller, S.; Ruzicka, T.; Zlotnik, A.; Homey, B. IL-31: A new link between T cells and pruritus in atopic skin inflammation. J. Allergy Clin. Immunol. 2006, 117, 411-417. [CrossRef] [PubMed]

10. D'Auria, E.; Banderali, G.; Barberi, S.; Gualandri, L.; Pietra, B. Atopic dermatitis: Recent insight on pathogenesis and novel therapeutic target. Asian Pac. J. Allergy Immunol. 2016, 34, 98-108.

11. Tanaka, M.; Aiba, S.; Matsumura, N.; Aoyama, H.; Tagami, H. Prurigo nodularis consists of two distinct forms: Early-onset atopic and late-onset non-atopic. Dermatology 1995, 190, 269-276. [CrossRef]

12. Larson, V.A.; Tang, O.; Stander, S.; Miller, L.S.; Kang, S.; Kwatra, S.G. Association between prurigo nodularis and malignancy in middle-aged adults. J. Am. Acad. Dermatol. 2019. [CrossRef] [PubMed]

13. Diagnoses of HIV Infection in the United States and Dependent Areas. 2017. Available online: http: //www.cdc.gov/hiv/library/reports/hiv-surveillance.html (accessed on 2 August 2019).

14. Magand, F.; Nacher, M.; Cazorla, C.; Cambazard, F.; Marie, D.S.; Couppié, P. Predictive values of prurigo nodularis and herpes zoster for HIV infection and immunosuppression requiring HAART in French Guiana. Trans. R. Soc. Trop. Med. Hyg. 2011, 105, 401-404. [CrossRef] [PubMed]

15. Yang, M.; Tang, W.; Sang, Y.; Chen, X.; Hu, X. Prevalence of chronic kidney disease-associated pruritus among adult dialysis patients. Medicine 2018, 97, 10633.

16. Winhoven, S.M.; Gawkrodger, D.J. Nodular prurigo: Metabolic diseases are a common association. Clin. Exp. Dermatol. 2007, 32, 224-225. [CrossRef] [PubMed]

(C) 2019 by the authors. Licensee MDPI, Basel, Switzerland. This article is an open access article distributed under the terms and conditions of the Creative Commons Attribution (CC BY) license (http://creativecommons.org/licenses/by/4.0/). 